\title{
Biomechanical comparison of single-bundle versus double-bundle anterior cruciate ligament reconstruction: a meta-analysis
}

Jin-Young Oh, Kun-Tae Kim, Young-Jin Park, Hee-Chan Won, Jun-Il Yoo, Dong-Kyu Moon, Sung-Hee Cho and Sun-Chul Hwang ${ }^{*}$ (D)

\begin{abstract}
Background: Of the many issues regarding surgical techniques related to anterior cruciate ligament reconstruction $(A C L R)$, single-bundle (SB) or double-bundle (DB) ACLR is one of the most debated topics. However, it is unclear which of the techniques yields better outcomes after ACLR for ACL injury. The purpose of this meta-analysis was to compare the benefits of SB versus DB ACLR in terms of biomechanical outcomes.

Methods: The electronic databases MEDLINE, Embase, the Cochrane Central Register of Controlled Trials, Web of Science, and Scopus were searched for relevant articles comparing the outcomes of SB-ACLR versus DB-ACLR that were published until November 2019.

Results: Seventeen biomechanical studies were included. The anterior laxity measured using the anterior drawer test showed significantly better results in DB-ACLR when compared with SB-ACLR. In addition, outcomes of the anterior tibial translation test under a simulated pivot shift presented with better results at low flexion and $30^{\circ}$ in DB-ACLR, compared with SB-ACLR. However, there were no significant biomechanical differences between the groups in internal rotation.

Conclusions: The present study demonstrated that both techniques for ACLR are associated with restoration of normal knee kinematics. DB-ACLR is superior to SB-ACLR in terms of restoration of anteroposterior stability. However, which technique yields better improvement in internal rotation laxity, and internal rotation laxity under a simulated pivot shift at a specific angle, remains unclear.
\end{abstract}

Level of evidence: This is a level II meta-analysis.

Keywords: Anterior cruciate ligament, Reconstruction, Single-bundle, Double-bundle, Biomechanical

\section{Background}

There are various surgical methods for treating anterior cruciate ligament $(\mathrm{ACL})$ injuries. Concerning these methods, there are differences of opinion among surgeons regarding single-bundle ACL reconstruction (SB-ACLR) and doublebundle ACL reconstruction (DB-ACLR). In past years, to

\footnotetext{
* Correspondence: hscspine@gnu.ac.kr

Department of Orthopaedic Surgery, Gyeongsang National University School of Medicine and Gyeongsang National University Hospital, 15, Jinju-daero 816 beon-gil, Jinju-si, Gyeongsangnam-do, Republic of Korea 660-751
}

reconstruct the injured $\mathrm{ACL}$, the single-bundle $(\mathrm{SB})$ procedure has been a standard surgical option. However, degenerative changes or arthrofibrosis remains a major concern after ACL reconstruction or other such surgical interventions $[1$, 2]. Arthrofibrosis or degenerative joint disease (DJD), which causes osteoarthritis, has been attributed to inefficient control of tibial rotation after SB-ACLR [3-7]. In addition, recent biomechanical studies have reported that SB-ACLR cannot restore normal anterior translation or rotatory laxity $[5,8]$. To further improve the current SB-ACLR techniques

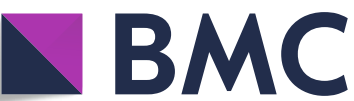

Part of Springer Nature (c) The Author(s). 2020 Open Access This article is licensed under a Creative Commons Attribution 4.0 International License, which permits use, sharing, adaptation, distribution and reproduction in any medium or format, as long as you give appropriate credit to the original author(s) and the source, provide a link to the Creative Commons licence, and indicate if changes were made. The images or other third party material in this article are included in the article's Creative Commons licence, unless indicated otherwise in a credit line to the material. If material is not included in the article's Creative Commons licence and your intended use is not permitted by statutory regulation or exceeds the permitted use, you will need to obtain permission directly from the copyright holder. To view a copy of this licence, visit http://creativecommons.org/licenses/by/4.0/. The Creative Commons Public Domain Dedication waiver (http://creativecommons.org/publicdomain/zero/1.0/) applies to the data made available in this article, unless otherwise stated in a credit line to the data. 
and provide a greater understanding of the ACL anatomy, DB-ACLR techniques are being advocated to more closely reproduce the native anatomy of the ACL and potentially enhance the stability of the knee joint [9-11]. Despite an apparent theoretical advantage associated with the reconstruction of both bundles of the ACL, a consensus regarding the superiority of DB-ACLR over the conventional SB-ACLR has yet to be established [11-13]. Over the past decade, the biomechanics of ACL have been investigated in various experimental settings. Nonetheless, concerns regarding the choice of techniques for restoration of normal knee biomechanics persist. Among the various surgical issues of ACLR such as graft type, the methods of fixation, and the number of bundles, one of the critical controversies in ACLR relates to the role of $\mathrm{DB}$ reconstruction in biomechanical outcomes compared with SB reconstruction.

Recently, some studies [14-18] have shown a comparison of excellence between SB-ACLR or DB-ACLR, but the results are still unclear, and quantitative analyses of biomechanical results are insufficient. Thus, the purpose of the present study was to perform a meta-analysis to compare the biomechanical outcomes of SB- ACLR versus DB-ACLR and determine their relative effectiveness in anterior tibial translation (ATT), internal rotation, or pivot in the setting of ACLR. We hypothesized that DBACLR is better than SB-ACLR in controlling anterior stability and rotational stability.

\section{Materials and methods}

\section{Study selection}

We searched multiple databases to identify studies comparing biomechanical outcomes of ACLR in subjects who underwent $\mathrm{SB}$ or $\mathrm{DB}$ reconstruction. This study was based on the Cochrane Review methods, and the reporting was in accordance with the statement on Preferred Reporting Items for Systematic Reviews and Meta-Analyses (PRISMA). To identify relevant studies, we used the controlled vocabulary and free text words described in Additional file 2 to search the MEDLINE, Embase, Cochrane Central Register of Controlled Trials, Web of Science, and Scopus databases. We identified all relevant studies regardless of language, publication type (article, poster, conference article, instructional course lecture, etc.), publication journal, and publication year. This search was updated in November 2019 and includes reference lists of the studies and any review articles identified.

\section{Eligibility criteria}

Studies were included in our investigation if (1) the studies compared biomechanical outcomes of SB-ACLR and DBACLR, (2) the subjects were human or human cadavers who received ACLR using SB or DB reconstruction, and (3) the comparative studies were controlled under laboratory settings. However, non-comparative studies of the effects of surgical technique, single-arm studies, which only described SB-ACLR or DB-ACLR, or studies that just recommended surgical treatment for ACL injury were excluded.

\section{Data collection and analysis}

Two authors independently assessed the titles or abstracts of studies identified by the search strategy, and subsequently full papers were assessed for final inclusion. Uncertainty about study inclusion was resolved through discussion and consensus. Eligible data were independently abstracted onto predefined forms by the authors and reviewed for accuracy. We collected data on study characteristics (including authors, journal, publication year, study design, and level of evidence) and patient demographics (sex, age, number of subjects, graft type or surgical techniques [SB or DB] used for reconstruction) (Table 1). Results of biomechanical studies, including ATT, internal rotation, and ATT with pivot of the tibia and internal rotation, with standard deviation (SD) of demographic data and biomechanical outcomes between the two groups were determined.

\section{Assessment of methodological quality}

Two investigators independently assessed the methodological qualities of each biomechanical study using the Quality Appraisal for Cadaveric Studies (QUACS) scale. The QUACS scale is highly reliable and presents strong construct validity for anatomical research [19]. Any disagreement between the authors was resolved through discussion or review by the third investigator.

\section{Statistical analysis}

The main purpose of this review was to evaluate the restoration of normal knee kinematics after ACLR using SB and $\mathrm{DB}$ techniques. In biomechanical studies, restoration is based mainly on knee stability such as ATT, internal rotation, ATT under simulated pivot shift, and internal rotation of tibia under pivot shift. To evaluate reconstructed knee stability, we calculated the mean \pm SD of each result of the SB and DB techniques and analyzed the differences in the outcome parameters between the groups. Review Manager (RevMan) version 5.3 (the Cochrane Collaboration, Software Update, Oxford) was used to estimate the overall pooled effect size for each outcome. A metaanalysis of the included studies was done using a randomeffects model. For continuous outcomes, we conducted standard mean difference (SMD) calculation with a 95\% confidence interval (CI) using the inverse variance method. Statistical heterogeneity among the studies was assessed using the $I$-squared $\left(I^{2}\right)$ index, with values of $25 \%, 50 \%$, and $75 \%$ considered as low, moderate, and high, respectively, and Cochran's Q statistic (chi-squared test). A $P$ value < 0.10 was defined as a significant degree of heterogeneity. 
Table 1 Summary of study characteristics

\begin{tabular}{|c|c|c|c|c|c|c|c|c|}
\hline Study & Journal & Year & $\begin{array}{l}\text { Study } \\
\text { design }\end{array}$ & Level of evidence & $\begin{array}{l}\text { Bundle } \\
\text { type }\end{array}$ & Age (years) & $\begin{array}{l}\operatorname{Sex}(M: \\
\text { F) }\end{array}$ & Graft \\
\hline \multirow{2}{*}{$\begin{array}{l}\text { Albuquerque } \\
\text { et al. }\end{array}$} & \multirow[t]{2}{*}{ Clinics (Sao Paulo) } & \multirow[t]{2}{*}{2007} & \multirow[t]{2}{*}{ CLS } & \multirow{2}{*}{$\begin{array}{l}\text { Level of evidence } \\
\text { (II) }\end{array}$} & SB:10 & \multirow{2}{*}{$\begin{array}{l}46.7(27- \\
67)\end{array}$} & \multirow[t]{2}{*}{$7: 3$} & QBTG (10) \\
\hline & & & & & DB:10 & & & QBTG (10) \\
\hline \multirow[t]{2}{*}{ Sbihi et al. } & \multirow{2}{*}{$\begin{array}{l}\text { Rev Chir Orthop Reparatrice Appar } \\
\text { Mot }\end{array}$} & \multirow[t]{2}{*}{2004} & \multirow[t]{2}{*}{ CLS } & \multirow{2}{*}{$\begin{array}{l}\text { Level of evidence } \\
\text { (II) }\end{array}$} & SB:8 & \multirow[t]{2}{*}{ NP } & \multirow[t]{2}{*}{ NP } & SemiT and gracilis (8) \\
\hline & & & & & DB:8 & & & SemiT and gracilis (8) \\
\hline \multirow[t]{2}{*}{ Ho et al. } & \multirow[t]{2}{*}{ Arthroscopy } & \multirow[t]{2}{*}{2009} & \multirow[t]{2}{*}{ CLS } & \multirow{2}{*}{$\begin{array}{l}\text { Level of evidence } \\
\text { (II) }\end{array}$} & SB:8 & \multirow{2}{*}{$\begin{array}{l}68.8(51- \\
83)\end{array}$} & \multirow[t]{2}{*}{$4: 4$} & SemiT and gracilis (8) \\
\hline & & & & & DB:8 & & & SemiT and gracilis (8) \\
\hline \multirow[t]{2}{*}{ Mae et al. } & \multirow[t]{2}{*}{ Arthroscopy } & \multirow[t]{2}{*}{2001} & \multirow[t]{2}{*}{ CLS } & \multirow{2}{*}{$\begin{array}{l}\text { Level of evidence } \\
\text { (II) }\end{array}$} & SB:7 & \multirow[t]{2}{*}{$75(67-86)$} & NP & SemiT and gracilis (7) \\
\hline & & & & & DB:7 & & & SemiT and gracilis (7) \\
\hline Seon et al. & Am J Sports Med. & 2010 & CLS & $\begin{array}{l}\text { Level of evidence } \\
\text { (II) }\end{array}$ & SB:10 & NP $(47-60)$ & $6: 4$ & $\begin{array}{l}\text { SemiT and/or gracilis } \\
\text { (10) }\end{array}$ \\
\hline & & & & & DB:10 & & & $\begin{array}{l}\text { SemiT and/or gracilis } \\
\text { (10) }\end{array}$ \\
\hline Yagi et al. & Am J Sports Med. & 2002 & CLS & $\begin{array}{l}\text { Level of evidence } \\
\text { (II) }\end{array}$ & SB:10 & NP (44-60) & NP & $\begin{array}{l}\text { SemiT and/or gracilis } \\
\text { (10) }\end{array}$ \\
\hline & & & & & DB:10 & & & SemiT and/or racilis (10) \\
\hline Yamamoto et al. & Am J Sports Med. & 2004 & CLS & $\begin{array}{l}\text { Level of evidence } \\
\text { (II) }\end{array}$ & SB:10 & $\begin{array}{l}48.6(39- \\
55)\end{array}$ & NP & $\begin{array}{l}\text { SemiT and/or gracilis } \\
\text { (10) }\end{array}$ \\
\hline & & & & & DB:10 & & & $\begin{array}{l}\text { SemiT and/or gracilis } \\
\text { (10) }\end{array}$ \\
\hline Nohmi et al. & Sports Med Arthrosc Rehabil Ther & 2012 & CLS & Level of evidence & SB:8 & $70.6(18-$ & NP & SemiT and/or gracilis (8) \\
\hline & & & & & $\mathrm{DB}: 8$ & & & SemiT and/or gracilis (8) \\
\hline Kondo et al. & Am J Sports Med. & 2010 & CLS & Level of evidence & SB:8 & $62.1(31-$ & NP & SemiT and gracilis (8) \\
\hline & & & & & DB:8 & & & SemiT and gracilis (8) \\
\hline Goldsmith et al. & Am J Sports Med. & 2013 & CLS & $\begin{array}{l}\text { Level of evidence } \\
\text { (II) }\end{array}$ & SB:9 & $\begin{array}{l}46.7(46- \\
58)\end{array}$ & $6: 3$ & $\begin{array}{l}\text { Bovine extensor tendon } \\
\text { (9) }\end{array}$ \\
\hline & & & & & DB:9 & & & $\begin{array}{l}\text { Bovine extensor tendon } \\
\text { (9) }\end{array}$ \\
\hline Lord et al. & Knee Surg Sports Traumatol Arthrosc & 2016 & CLS & Level of evidence & SB:9 & $66(57-78)$ & 4:5 & SemiT and gracilis (9) \\
\hline & & & & & DB:9 & & & SemiT and gracilis (9) \\
\hline Gadikota et al. & Am J Sports Med. & 2009 & CLS & Level of evidence & $\mathrm{SB}: 8$ & NP (59-64) & NP & SemiT and gracilis (8) \\
\hline & & & & & DB:8 & & & SemiT and gracilis (8) \\
\hline Kim et al. & Knee Surg Sports Traumatol Arthrosc & 2015 & CLS & Level of evidence & SB:10 & $59.8(49-$ & 10:0 & Quadriceps tendon (10) \\
\hline & & & & & DB:10 & & & Quadriceps tendon (10) \\
\hline Herbort et al. & Am J Sports Med. & 2015 & CLS & $\begin{array}{l}\text { Level of evidence } \\
\text { (II) }\end{array}$ & SB:10 & $\begin{array}{l}76.3(63- \\
86)\end{array}$ & NP & $\begin{array}{l}\text { Porcine flexor tendon } \\
\text { (10) }\end{array}$ \\
\hline & & & & & DB:10 & & & $\begin{array}{l}\text { Porcine flexor tendon } \\
\text { (10) }\end{array}$ \\
\hline Musahl et al. & Am J Sports Med. & 2011 & CLS & Level of evidence & SB:10 & $62(57-70)$ & NP & Gracilis (10) \\
\hline & & & & & DB:10 & & & Gracilis (10) \\
\hline Komzák et al. & Eur J Trauma Emerg Surg & 2017 & CLS & $\begin{array}{l}\text { Level of evidence } \\
\text { (II) }\end{array}$ & SB:20 & $\begin{array}{l}27.5(17- \\
42)\end{array}$ & 23:17 & $\begin{array}{l}\text { SemiT and/or gracilis } \\
\text { (20) }\end{array}$ \\
\hline & & & & & DB:20 & & & $\begin{array}{l}\text { SemiT and/or gracilis } \\
\text { (20) }\end{array}$ \\
\hline Suzuki et al. & Arthroscopy & 2019 & CLS & Level of evidence & SB: 22 & $84(72-92)$ & NP & SemiT (22) \\
\hline & & & & & DB: 22 & & & SemiT(22)s \\
\hline
\end{tabular}

CLS controlled laboratory study, SB single-bundle, DB double-bundle, QBTG quadriceps bone-tendon graft, SemiT semitendinosus tendon, NP not provided 


\section{Results}

\section{Identification of studies}

A total of 65,973 relevant articles were initially identified. Of these, 31,674 were duplicated in the databases. After screening the remaining 34,299 articles using titles and abstracts, all but 35 were excluded because they were not relevant to the purpose of the present study. A full-text review of the 35 articles resulted in exclusion of articles because they lacked vital data, such as experimental outcomes. The exclusion criteria for articles included no investigation of the effect of individual ACLR techniques, biomechanical study using fine element method, review article, study evaluated patients who underwent conservative treatment for ACL injuries, or research involved animal studies. Finally, 17 biomechanical studies [20-36] were included for data extraction and meta-analysis (see Fig. 1).

\section{Quality of the included studies}

To evaluate the methodologic quality, we used the QUACS scale for biomechanical studies (maximum 13 points). All subjects of the biomechanical studies had QUACS scale scores $\geq 10$ points (range, 10-13) points, indicative of low risk of bias of the included biomechanical studies.

\section{Outcomes of knee stability in biomechanical studies \\ Anterior tibial translation}

Fourteen studies reported ATT at low flexion $\left(0-10^{\circ}\right)$, $30^{\circ}, 60^{\circ}$, and $90^{\circ}$ knee flexion angle in SB and DB groups (SB group/DB group: $93 / 93$ at low flexion, $112 / 112$ at $30^{\circ}, 109 / 109$ at $60^{\circ}$, and $101 / 101$ at $90^{\circ}$ ), and the remaining studies were excluded for insufficient data. Significant differences were found in ATT at all the knee flexion angles measured among the SB and $\mathrm{DB}$ groups (low flexion: $\mathrm{SMD}=0.62,95 \% \mathrm{CI}=$ 0.25 to $0.99, I^{2}=32 \% ; 30^{\circ}: \mathrm{SMD}=0.43,95 \% \mathrm{CI}=0.13$ to $0.73, I^{2}=39 \% ; 60^{\circ}$ : $\mathrm{SMD}=0.32,95 \% \mathrm{CI}=0.00$ to $0.63, I^{2}=0 \% ; 90^{\circ}: \mathrm{SMD}=0.33,95 \% \mathrm{CI}=0.07$ to 0.60 , $I^{2}=5 \%$ ) (see Fig. 2). Therefore, anterior laxity measured using the anterior drawer test showed statistically significant results of more resistance in DBACLR when compared with SB-ACLR.

Records identified through database search

Medline $(n=10,816)$, EMBASE $(n=23,210)$, Cochrane $(n=1,533)$, Web of Science $(n=10,230)$, SCOPUS $(n=20,184)$

Total $(n=65,973)$
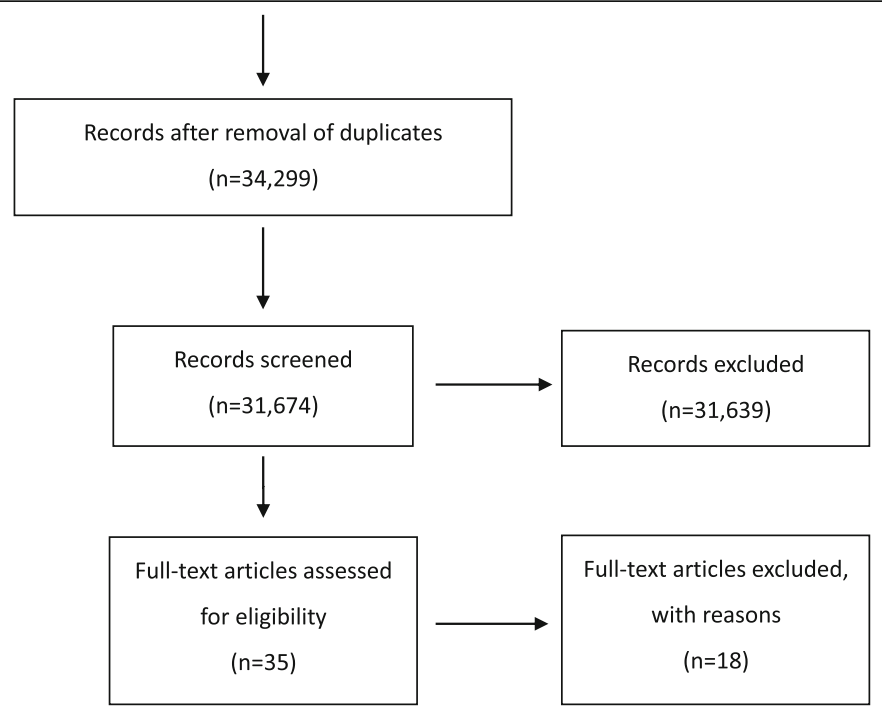

Studies included in qualitative and quantitative synthesis

(Finally, $\mathrm{n}=17$ )

Fig. 1 Preferred Reporting Items of Systematic Reviews and Meta-Analysis (PRISMA) flow diagram 

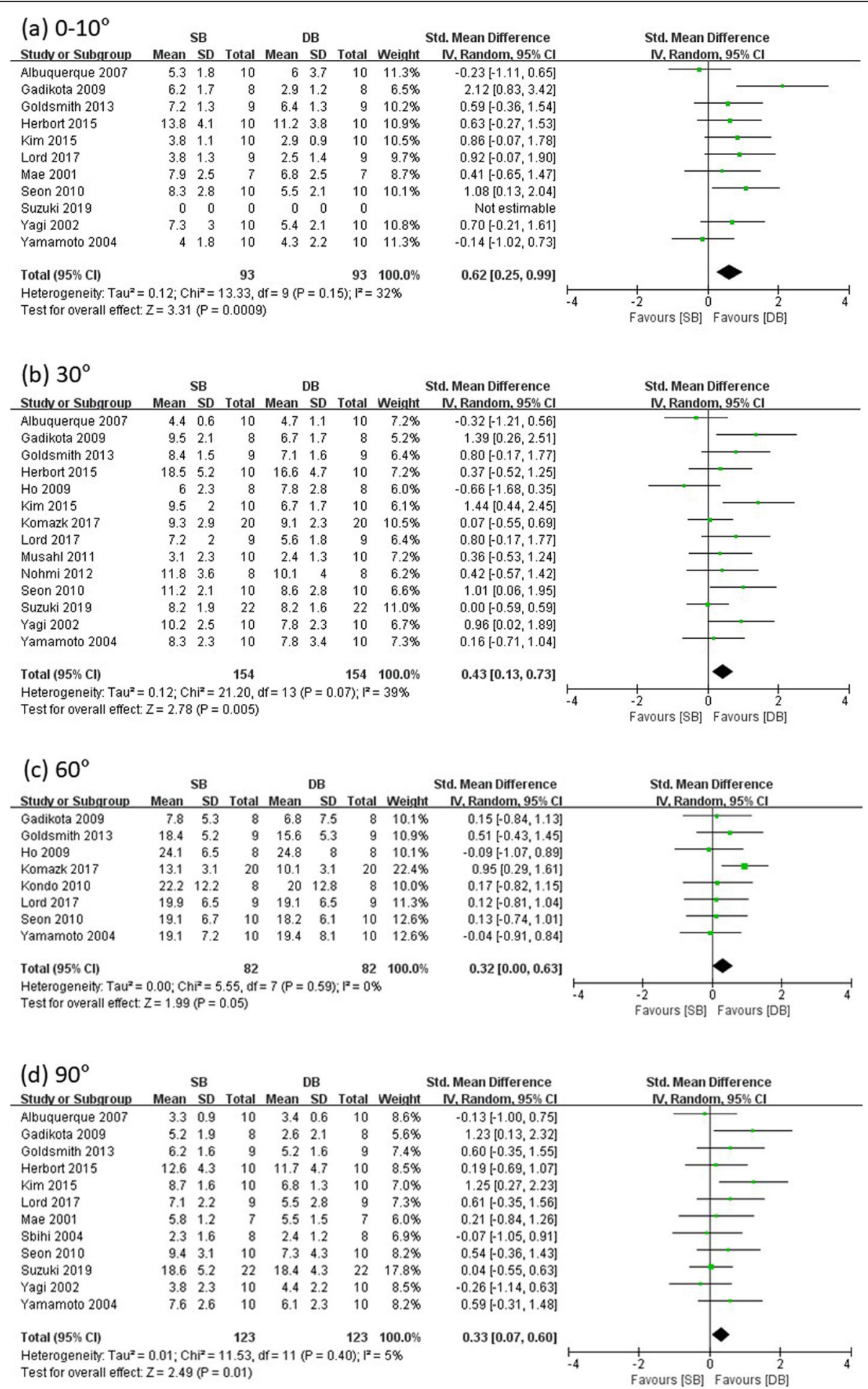

Fig. 2 Forest plot showing standard mean difference in anterior tibial translation at different knee flexion angles: results of single-bundle versus double-bundle $\mathrm{ACL}$ reconstruction. a low flexion $\left(0-10^{\circ}\right)$, b $30^{\circ}, \mathbf{c} 60^{\circ}, \mathbf{d} 90^{\circ}$. SB single-bundle, DB double-bundle, Std standard, SD standard deviation, $I V$ inverse variance, $C l$ confidence interval $d f$ degrees of freedom

\section{Internal rotation laxity}

Eight studies reported internal rotation laxity at different knee flexion angles in SB and DB groups (SB group/DB group: $44 / 44$ at low flexion, $62 / 62$ at $30^{\circ}, 33 / 33$ at $60^{\circ}, 34 /$ 34 at $90^{\circ}$ ). The other studies did not include an internal rotation test. There were no significant differences in 


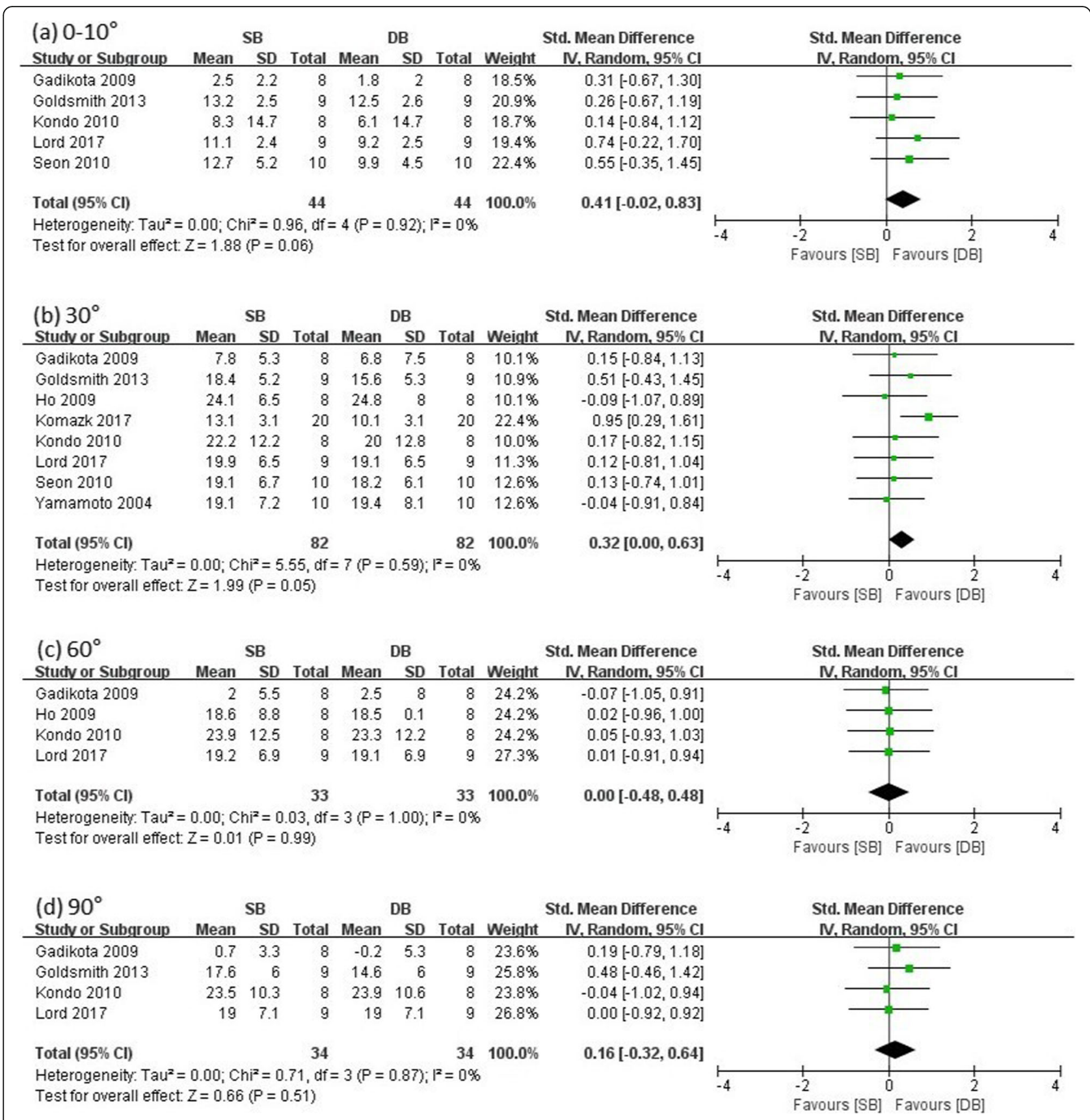

Fig. 3 Forest plot showing standard mean difference in internal rotation at different knee flexion angles: results of single-bundle versus doublebundle $A C L$ reconstruction. a low flexion $\left(0-10^{\circ}\right)$, b $30^{\circ}, \mathbf{c} 60^{\circ}, \mathbf{d} 90^{\circ}$. SB single-bundle, DB double-bundle, Std standard, SD standard deviation, $\mathrm{N}$ inverse variance, $\mathrm{Cl}$ confidence interval $d f$ degrees of freedom

internal rotation laxity between the $\mathrm{SB}$ and $\mathrm{DB}$ groups at all evaluated knee flexion angles except $30^{\circ}$ (low flexion: $\mathrm{SMD}=0.41,95 \% \mathrm{CI}=-0.02$ to $0.83, I^{2}=0 \% ; 30^{\circ}: \mathrm{SMD}=$ $0.32,95 \% \mathrm{CI}=0.00$ to $0.63, I^{2}=0 \% ; 60^{\circ}: \mathrm{SMD}=0.00,95 \%$ $\mathrm{CI}=-0.48$ to $0.48, I^{2}=0 \% ; 90^{\circ}: \mathrm{SMD}=0.16,95 \% \mathrm{CI}=-$ 0.32 to $0.64, I^{2}=0 \%$ ) (see Fig. 3). Therefore, internal rotation laxity showed statistically no difference between the two groups, and DB-ACLR was more resistant at $30^{\circ}$ for the internal rotation test.

\section{Anterior tibial translation under simulated pivot shift}

Ten studies reported on ATT under simulated pivot shift at low and $30^{\circ}$ knee flexion angles in SB and DB groups (SB group/DB group: $64 / 64$ at low flexion, $94 / 94$ at $30^{\circ}$ ). The 


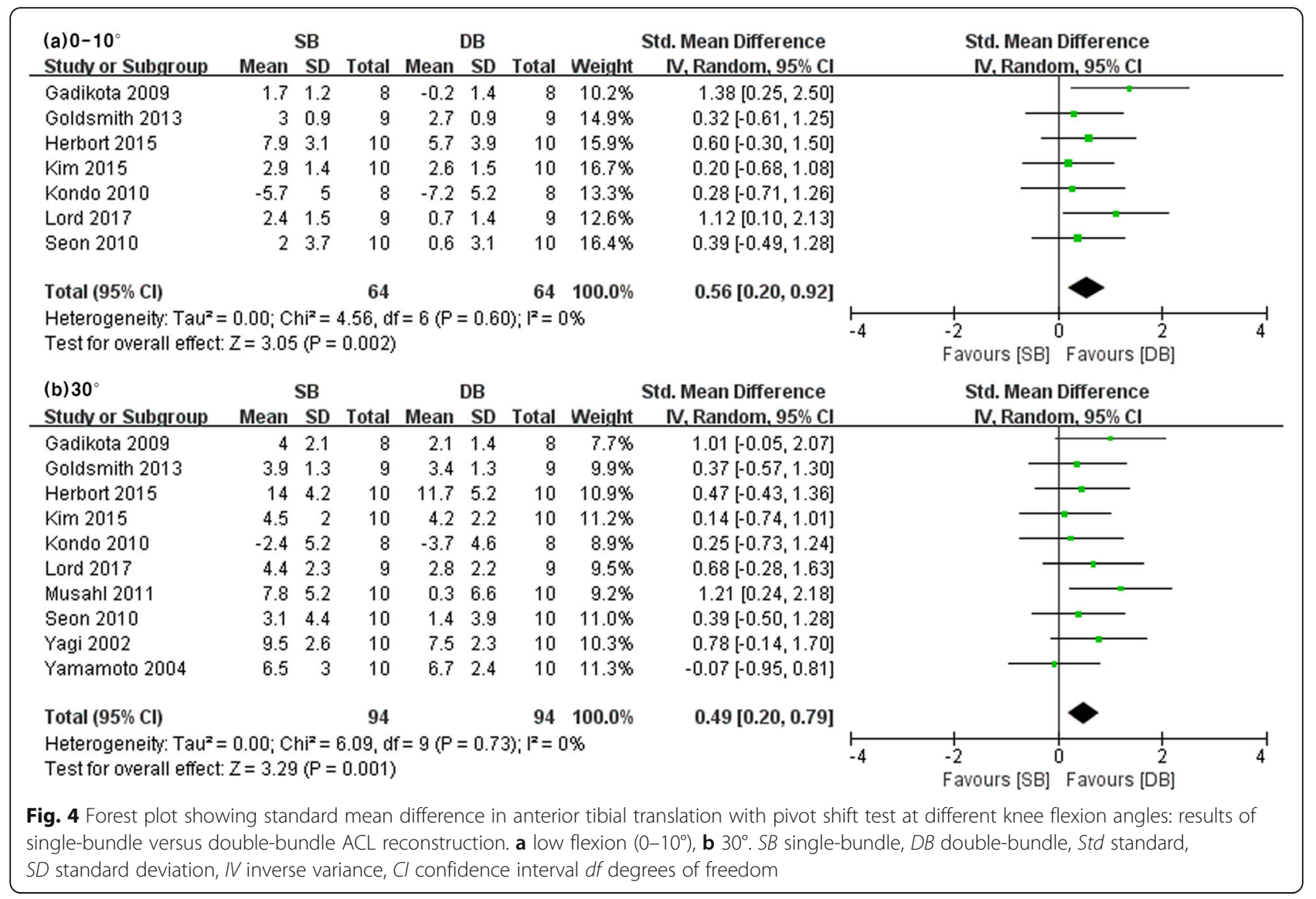

other studies did not include information pertaining to ATT under simulated pivot shift. Significant differences were found in ATT under simulated pivot shift at low and $30^{\circ}$ knee flexion angles between the SB and DB groups (low flexion: $\mathrm{SMD}=0.56,95 \% \mathrm{CI}=0.20$ to $0.92, I^{2}=0 \% ; 30^{\circ}$ :
$\mathrm{SMD}=0.49,95 \% \mathrm{CI}=0.20$ to $0.79, I^{2}=0 \%$ ) (see Fig. 4). Therefore, anterior rotational laxity measured using the anterior drawer test under a pivot shift test showed statistically significant results of more resistance in DB-ACLR when compared with SB-ACLR.

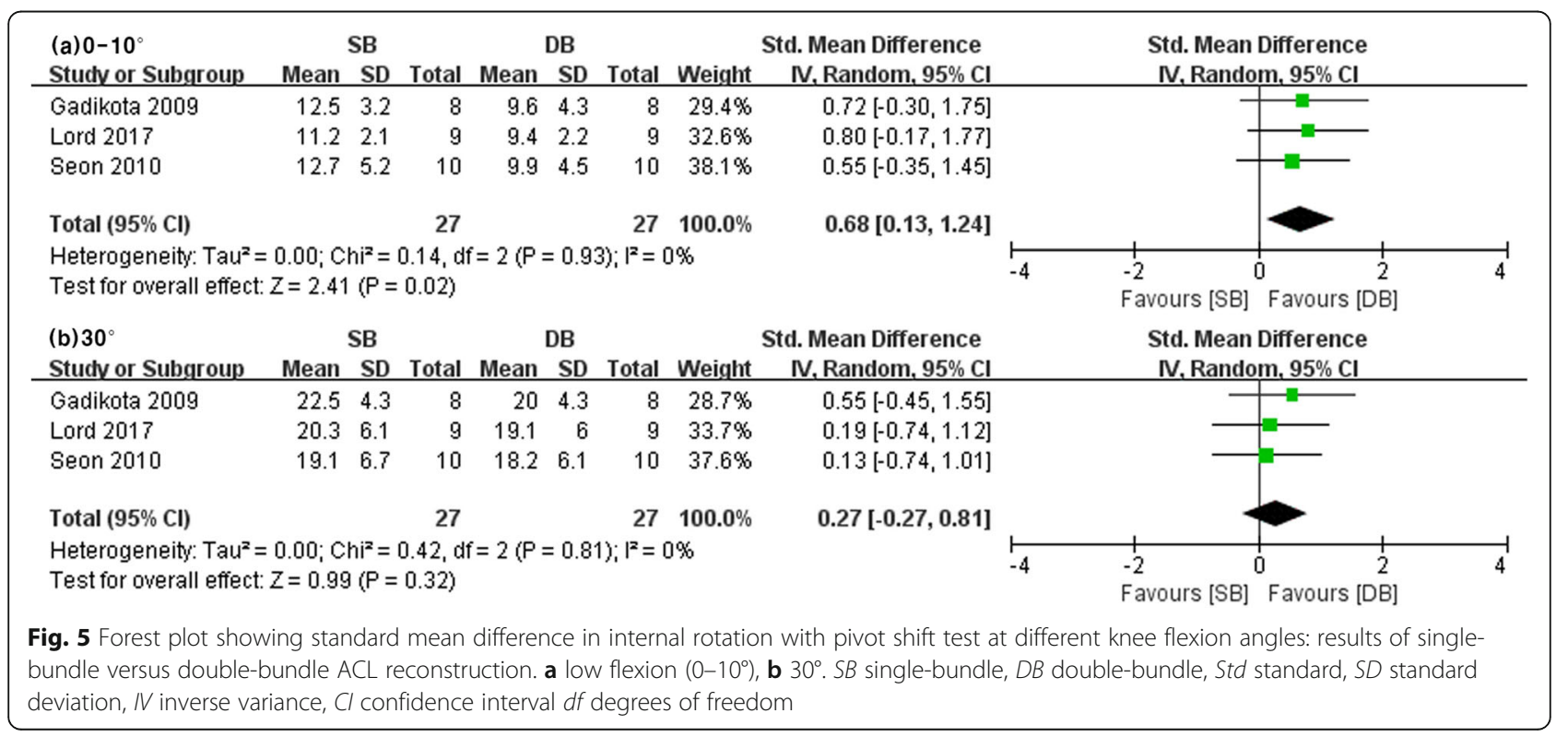




\section{Internal rotation laxity under simulated pivot shift}

Three studies reported internal rotation of the tibia under pivot shift at low flexion and $30^{\circ}$ knee flexion angles in SB and DB groups (SB group/DB group: 27/27 at low flexion, $27 / 27$ at $30^{\circ}$ ). The other studies did not investigate internal rotation laxity under simulated pivot shift. There were differences in that DB-ACLR was more resistant in internal rotation laxity under simulated pivot shift at low knee flexion angles between the SB and DB groups. However, no significant differences were noted at $30^{\circ}$ knee flexion angles between the $\mathrm{SB}$ and $\mathrm{DB}$ groups (low flexion: $\mathrm{SMD}=0.68,95 \% \mathrm{CI}=0.13$ to 1.24 , $I^{2}=0 \% ; 30^{\circ}: \mathrm{SMD}=0.27,95 \% \mathrm{CI}=-0.27$ to $0.81, I^{2}=$ 0\%) (see Fig. 5).

\section{Discussion}

In this meta-analysis, we assessed the evidence from controlled laboratory studies that compared outcomes with SB-ACLR versus DB-ACLR. The most important finding of this study was that ATT measured with the anterior drawer test favored DB-ACLR at all knee flexion angles. Another important finding showed that ATT measured under pivot shift at low and $30^{\circ}$ knee flexion angles and internal rotation laxity under pivot shift at low flexion presented with superior outcome in DBACLR. However, we found no evidence of differences in internal rotation laxity associated with SB-ACLR and DB-ACLR at all knee flexion angles evaluated. Thus, the results of the meta-analysis supported our hypothesis that DB-ACLR is more effective than SB-ACLR in controlling anterior stability, although the association between the number of bundles and rotational instability remains unclear. Because of the low heterogeneity of results between the included studies, the meta-analysis strongly suggested that DB-ACLR was superior to SBACLR in terms of anterior laxity; however, the superiority of DB-ACLR for rotational laxity was inconclusive.

The ACL has a parallel array of collagen fascicles that are usually divided into anteromedial (AM) and posterolateral (PL) segments according to their attachment sites. The AM bundle plays a critical role in resisting tibial anterior drawer-the primary function of the $\mathrm{ACL}$ - while the PL bundle is tight near knee extension in tibial rotational laxity. The PL bundle was dominant near knee extension in a few studies [37-39], particularly when resisting anterior drawer, and its contribution reduced rapidly with knee flexion through $30^{\circ}$ [40]. One of the main rationales for the introduction of DB-ACLR was to address the persistent anteroposterior (AP) instability and rotational instability of the knee after conventional surgical interventions [41]. Such rationales coincide with this study, which may represent evidence supporting DB-ACLR.
Several biomechanical studies have investigated the advantage in AP stability of DB-ACLR relative to SB-ACLR. In this meta-analysis performed on the basis of biomechanical studies, the DB-ACLR presented with more favorable stability at all angles with respect to AP stability. Despite controversies on whether DB-ACLR more closely restores AP laxity compared to SB-ACLR, many studies showed that the anterior laxity of both reconstructions did not differ statistically as compared to those of normal knee anterior stability. Some authors reported that DB-ACLR has no advantage in more anatomic structure and prevents ATT [22], and some reported that there was no clinically significant difference in AP stability between SB- and DB-ACLR $[42,43]$. By contrast, others reported that DB-ACLR is superior biomechanically at all angles [33], and a metaanalysis $[44,45]$ reported that DB-ACLR is clinically more excellent. This is in line with the results of this study, and it is the result of strengthening the theoretical evidence of DB-ACLR.

The results of this study showed that DB-ACLR had a significant benefit in ATT at low flexion angle and $30^{\circ}$ in the pivot shift test. In accordance with our results, Musahl et al. [36] reported that DB-ACLR had a more favorable outcome in terms of ATT in a pivot shift test at $30^{\circ}$ when compared with SB-ACLR. Furthermore, Lord et al. [32] reported a lack of significant difference at $30^{\circ}$; however, DB-ACLR presented with a more favorable outcome in terms of ATT at low flexion, warranting further studies. Conversely, Herbort et al. [35] and Kondo et al. [30] reported no significant difference between the SB- and DBACLR groups at all angles in the pivot shift test. Goldsmith et al. [31] and Kim et al. [34] also showed that there was no significant difference between the two groups when ATT was measured in the pivot shift test at a low degree of flexion or $30^{\circ}$. In terms of ATT with the pivot shift test, our results indicate that DB-ACLR resulted in AP stability compared with SB-ACLR at low knee flexion angle and $30^{\circ}$ in a pivot shift test between two groups. Gadikota et al. [33], Lord et al. [32], and Seon et al. [26] reported that internal rotation did not differ between the two groups at low flexion or $30^{\circ}$ in the pivot shift test. However, such differences can be changed by experimental devices and conditions. A study using an accelerometer (Kisler, Switzerland) reported that the rotational acceleration was decreased by DB-ACLR to the intact level of the acceleration and that anatomic DB-ACLR is more dominant in restoring dynamic rotational laxity and biomechanically superior in terms of anatomic structure to SB-ACLR. Regarding internal rotation, DB-ACLR is more resistant in internal rotation at $30^{\circ}$, but Maeyama et al. [46] show no statistical difference between two groups in their study. Thus, a meta-analysis shows that DB-ACLR is more resistant at $30^{\circ}$ internal rotation, but this may be due to the large number of knees studied. 
The included biomechanical studies compared outcomes of AP stability, ATT with pivot shift, internal rotation laxity, and internal rotation with pivot shift of $\mathrm{SB}$ and $\mathrm{DB}$ techniques for ACL injuries. All the biomechanical studies scored $\geq 10$ points on the QUACS scale, indicating a low risk of bias of the included studies and their eligibility for the meta-analysis. In addition, screening and data extraction were carried out by two independent and blinded reviewers, which is one of the strengths of our study. Although a previous metaanalysis focused on biomechanical studies of SB- and DB-ACLR, only 7 studies were involved in that analysis, which reported no significant differences in terms of biomechanical parameters. Thus, this study provides strong evidence regarding ACLR and valuable evidence in support of DB-ACLR.

However, despite its strengths, our study has some limitations. First of all, this study is a meta-analysis based on time zero studies that were not reflected after a period of time in vivo such as healing and biological responses. While it is not possible to conclude how the results may influence patient outcomes and clinical practice other than the outcome on the day of surgery, time zero studies are commonly suitable for providing guidelines for clinical practice in terms of procedure or device selection, as they provide baseline information. Second, a relatively small number of studies were included in this meta-analysis. In addition, several included studies used elderly cadaveric knees for ACLR; hence, the tissue properties and bone density may have differed from those of younger patients with sports injuries, which may carry a risk of bias. Moreover, there are few previously published original articles on this topic, which is an absolute limitation. The inclusion of 17 in vitro studies and the disparities of testing protocols may significantly contribute to the generation of bias when comparing mean differences of these studies. In order to compensate for such bias, additional studies were included, and powerful evidence was drawn through calculation of the SMD, as compared with previous metaanalyses. Third, technical factors of surgery that may affect results following ACLR need to be controlled, including those associated with SB or DB techniques, as well as graft characteristics, tensioning protocol, and graft fixation methods. In other words, the methodologies of studies included in this meta-analysis showed heterogeneity.

Meta-analysis is a process to arrive at powerful conclusions by analyzing studies on a specific topic. However, it is impossible to include studies exclusively with a similar methodology, and the inclusion criteria suggested in the article were strictly adopted to minimize bias when selecting the studies and were based on recommendations from Cochrane Collaboration guidelines. Therefore, the risk of bias was minimized by including only comparative studies conducted under the same conditions, using a random- effects model, and calculating the SMD statistically. In the future, prospective studies that control for such independent factors through high-quality medical research are needed.

\section{Conclusions}

In conclusion, this meta-analysis suggested that DB-ACLR is biomechanically superior to SB-ACLR in terms of restoration of anterior laxity of the knee. However, the results on which technique provides better restoration in rotational instability remain inconclusive. To verify and strengthen our results, more high-quality randomized controlled trials are required.

\section{Supplementary information}

Supplementary information accompanies this paper at https://doi.org/10. 1186/s43019-020-00033-8.

Additional file 1. Supplemental materials I. Anterior tibial translation with anterior drawer force after single-bundle anterior cruciate ligament reconstruction and double-bundle anterior cruciate ligament reconstruction at the different knee flexion angles.

Additional file 2. Electronic Search Strategy on Each Database.

\section{Abbreviations \\ ACL: Anterior cruciate ligament; AM: Anteromedial; AP : Anteroposterior; ATT: Anterior tibial translation; Cl: Confidence interval; DB-ACLR: Double- bundle anterior cruciate ligament reconstruction; ITB: Iliotibial band; PL: Posterolateral; PRISMA: Preferred Reporting Items for Systematic Reviews and Meta-Analyses; QUACS: Quality Appraisal for Cadaveric Studies; SB: Single-bundle; SB-ACLR: Single-bundle anterior cruciate ligament reconstruction; SD: Standard deviation; SMD: Standard mean difference}

\section{Acknowledgements}

We thank Dr. Dong-Young Lee (Department of Orthopaedic Surgery, The Armed Forces.

Daegu Hospital, Gyeongsang, Korea) for providing advice on the RevMan and Cochrane data.

\section{Authors' contributions}

JYO and KTK interpreted the results and wrote the paper. YJP and HCW collected the data and performed the meta-analysis. JYY, DKM, and SHC contributed to the interpretation of the results. SCH totally supervised the project. All authors provided critical feedback, discussed the results, and read and approved the final manuscript.

\section{Funding}

No funding of any form was provided for this study.

Availability of data and materials

Not applicable.

Ethics approval and consent to participate

Not applicable.

Consent for publication

Not applicable.

Competing interests

The authors declare that they have no competing interests. 
Received: 12 October 2019 Accepted: 18 February 2020

Published online: 12 March 2020

\section{References}

1. Liden M, Sernert N, Rostgard-Christensen L, Kartus C, Ejerhed L (2008) Osteoarthritic changes after anterior cruciate ligament reconstruction using bone-patellar tendon-bone or hamstring tendon autografts: a retrospective, 7-year radiographic and clinical follow-up study. Arthroscopy 24:899-908

2. van der Hart CP, van den Bekerom MP, Patt TW (2008) The occurrence of osteoarthritis at a minimum of ten years after reconstruction of the anterior cruciate ligament. J Orthop Surg Res 3:24

3. Chouliaras V, Ristanis S, Moraiti C, Stergiou N, Georgoulis AD (2007) Effectiveness of reconstruction of the anterior cruciate ligament with quadrupled hamstrings and bone-patellar tendon-bone autografts: an in vivo study comparing tibial internal-external rotation. Am J Sports Med 35:189-196

4. Ristanis S, Stergiou N, Patras K, Tsepis E, Moraiti C, Georgoulis AD (2006) Follow-up evaluation 2 years after $A C L$ reconstruction with bone-patellar tendon-bone graft shows that excessive tibial rotation persists. Clinical J Sport Med 16:111-116

5. Woo SL, Kanamori A, Zeminski J, Yagi M, Papageorgiou C, Fu FH (2002) The effectiveness of reconstruction of the anterior cruciate ligament with hamstrings and patellar tendon. A cadaveric study comparing anterior tibial and rotational loads. J Bone Joint Surgery Am 84-A:907-914

6. Stergiou N, Ristanis S, Moraiti C, Georgoulis AD (2007) Tibial rotation in anterior cruciate ligament (ACL)-deficient and $\mathrm{ACL}$-reconstructed knees: a theoretical proposition for the development of osteoarthritis. Sports Med 37:601-613

7. Mayr HO, Weig TG, Plitz W (2004) Arthrofibrosis following ACL reconstruction-reasons and outcome. Arch Orthop Trauma Surg 124:518522

8. Lee MC, Seong SC, Lee S et al (2007) Vertical femoral tunnel placement results in rotational knee laxity after anterior cruciate ligament reconstruction. Arthroscopy 23:771-778

9. Radford WJ, Amis AA (1990) Biomechanics of a double prosthetic ligament in the anterior cruciate deficient knee. J B Joint Surg Br 72:1038-1043

10. Crawford C, Nyland J, Landes S et al (2007) Anatomic double bundle ACL reconstruction: a literature review. Knee Surg Sports Traumatol, Arthrosc 15: 946-964 discussion 945

11. Song EK, Oh LS, Gill TJ, Li G, Gadikota HR, Seon JK (2009) Prospective comparative study of anterior cruciate ligament reconstruction using the double-bundle and single-bundle techniques. Am J Sports Med 37:17051711

12. Tsuda E, Ishibashi Y, Fukuda A, Tsukada H, Toh S (2009) Comparable results between lateralized single- and double-bundle ACL reconstructions. Clin Orthop Relat Res 467:1042-1055

13. Meredick RB, Vance KJ, Appleby D, Lubowitz JH (2008) Outcome of singlebundle versus double-bundle reconstruction of the anterior cruciate ligament: a meta-analysis. Am J Sports Med 36:1414-1421

14. Aga C, Risberg MA, Fagerland MW et al (2018) No difference in the KOOS Quality of Life subscore between anatomic double-bundle and anatomic single-bundle anterior cruciate ligament reconstruction of the knee: a prospective randomized controlled trial with 2 years' follow-up. Am J Sports Med 46:2341-2354

15. Mayr HO, Bruder S, Hube R, Bernstein A, Suedkamp NP, Stoehr A (2018) Single-bundle ersus double-bundle anterior cruciate ligament reconstruction-5-year results. Arthroscopy 34:2647-2653

16. Belk JW, Kraeutler MJ, Houck DA, McCarty EC (2019) Knee osteoarthritis after single-bundle versus double-bundle anterior cruciate ligament reconstruction: a systematic review of randomized controlled trials. Arthroscopy 35:996-1003

17. Gobbi A, Whyte GP (2019) Anatomic double-bundle and single-bundle ACL reconstruction after $A C L$ rupture did not differ for quality of life at 2 years. J Bone Joint Surg Am 101:943

18. Yoon KH, Kim JS, Kim SJ, Park M, Park SY, Park SE (2019) Eight-year results of transtibial nonanatomic single-bundle versus double-bundle anterior cruciate ligament reconstruction: clinical, radiologic outcomes and survivorship. J Orthop Surg (Hong Kong) 27:2309499019840827

19. Wilke J, Krause F, Niederer D et al (2015) Appraising the methodological quality of cadaveric studies: validation of the QUACS scale. J Anat 226:440446
20. Suzuki T, Shino K, Yamakawa S et al (2019) A biomechanical comparison of single-, double-, and triple-bundle anterior cruciate ligament reconstructions using a hamstring tendon graft. Arthroscopy 35:896-905

21. Komzak M, Hart R, Feranec M, Smid P, Kocova R (2018) In vivo knee rotational stability 2 years after double-bundle and anatomic single-bundle ACL reconstruction. Eur J Trauma Emerg Surg 44:105-111

22. Albuquerque RF, Sasaki SU, Amatuzzi MM, Angelini FJ (2007) Anterior cruciate ligament reconstruction with double bundle versus single bundle: experimental study. Clinics 62:335-344

23. Sbihi A, Franceschi JP, Christel P, Colombet P, Djian P, Bellier G (2004) Anterior cruciate ligament reconstruction: biomechanical comparison on cadaver specimens using a single or double hamstring technique. Revue de chirurgie orthopedique et reparatrice de l'appareil moteur 90:643-650

24. Ho JY, Gardiner A, Shah V, Steiner ME (2009) Equal kinematics between central anatomic single-bundle and double-bundle anterior cruciate ligament reconstructions. Arthroscopy 25:464-472

25. Mae T, Shino K, Miyama T et al (2001) Single- versus two-femoral socket anterior cruciate ligament reconstruction technique: biomechanical analysis using a robotic simulator. Arthroscopy 17:708-716

26. Seon JK, Gadikota HR, Wu JL, Sutton K, Gill TJ, Li G (2010) Comparison of single- and double-bundle anterior cruciate ligament reconstructions in restoration of knee kinematics and anterior cruciate ligament forces. Am J Sports Med 38:1359-1367

27. Yagi M, Wong EK, Kanamori A, Debski RE, Fu FH, Woo SL (2002) Biomechanical analysis of an anatomic anterior cruciate ligament reconstruction. Am J Sports Med 30:660-666

28. Yamamoto Y, Hsu WH, Woo SL, Van Scyoc AH, Takakura Y, Debski RE (2004) Knee stability and graft function after anterior cruciate ligament reconstruction: a comparison of a lateral and an anatomical femoral tunnel placement. Am J Sports Med 32:1825-1832

29. Nohmi S, Ishibashi Y, Tsuda E, Yamamoto Y, Tsukada H, Toh S (2012) Biomechanical comparison between single-bundle and double-bundle anterior cruciate ligament reconstruction with hamstring tendon under cyclic loading condition. Sports Med Arthrosc Rehabil Ther Technol 4:23

30. Kondo E, Merican AM, Yasuda K, Amis AA (2010) Biomechanical comparisons of knee stability after anterior cruciate ligament reconstruction between 2 clinically available transtibial procedures: anatomic double bundle versus single bundle. Am J Sports Med 38:1349-1358

31. Goldsmith MT, Jansson KS, Smith SD, Engebretsen L, LaPrade RF, Wijdicks CA (2013) Biomechanical comparison of anatomic single- and doublebundle anterior cruciate ligament reconstructions: an in vitro study. Am J Sports Med 41:1595-1604

32. Lord BR, El-Daou H, Sabnis BM, Gupte CM, Wilson AM, Amis AA (2017) Biomechanical comparison of graft structures in anterior cruciate ligament reconstruction. Knee Surg Sports Traumatol Arthrosc 25:559-568

33. Gadikota HR, Seon JK, Kozanek M et al (2009) Biomechanical comparison of single-tunnel-double-bundle and single-bundle anterior cruciate ligament reconstructions. Am J Sports Med 37:962-969

34. Kim D, Asai S, Moon CW et al (2015) Biomechanical evaluation of anatomic single- and double-bundle anterior cruciate ligament reconstruction techniques using the quadriceps tendon. Knee Surg Sports Traumatol Arthrosc 23:687-695

35. Herbort M, Domnick C, Raschke MJ et al (2016) Comparison of knee kinematics after single-bundle anterior cruciate ligament reconstruction via the medial portal technique with a central femoral tunnel and an eccentric femoral tunnel and after anatomic double-bundle reconstruction: a human cadaveric study. Am J Sports Med 44:126-132

36. Musahl V, Bedi A, Citak M, O'Loughlin P, Choi D, Pearle AD (2011) Effect of single-bundle and double-bundle anterior cruciate ligament reconstructions on pivot-shift kinematics in anterior cruciate ligament- and meniscusdeficient knees. Am J Sports Med 39:289-295

37. Amis AA, Dawkins GP (1991) Functional anatomy of the anterior cruciate ligament. Fibre bundle actions related to ligament replacements and injuries. J Bone Joint Surg Br 73:260-267

38. Kurosawa H, Yamakoshi K, Yasuda K, Sasaki T (1991) Simultaneous measurement of changes in length of the cruciate ligaments during knee motion. Clin Orthop Relat Res 265:233-40. https://journals.Iww.com/ clinorthop/Abstract/1991/04000/Simultaneous_Measurement_of_Changes_ in Length_of.27.aspx.

39. Sapega AA, Moyer RA, Schneck C, Komalahiranya N (1990) Testing for isometry during reconstruction of the anterior cruciate ligament. Anatomical and biomechanical considerations. J Bone Joint Surg Am 72:259-267 
40. Amis AA (2012) The functions of the fibre bundles of the anterior cruciate ligament in anterior drawer, rotational laxity and the pivot shift. Knee Surg Sports Traumatol Arthrosc 20:613-620

41. Steckel H, Starman JS, Baums MH, Klinger HM, Schultz W, Fu FH (2007) The double-bundle technique for anterior cruciate ligament reconstruction: a systematic overview. Scand J Med Sci Sports 17:99-108

42. Suomalainen P, Jarvela T, Paakkala A, Kannus P, Jarvinen M (2012) Doublebundle versus single-bundle anterior cruciate ligament reconstruction: a prospective randomized study with 5-year results. Am J Sports Med 40: $1511-1518$

43. Ha JK, Lee DW, Kim JG (2016) Single-bundle versus double-bundle anterior cruciate ligament reconstruction: a comparative study with propensity score matching. Indian J Orthop 50:505-511

44. Xu M, Gao S, Zeng C et al (2013) Outcomes of anterior cruciate ligament reconstruction using single-bundle versus double-bundle technique: metaanalysis of 19 randomized controlled trials. Arthroscopy 29:357-365

45. Li YL, Ning GZ, Wu Q et al (2014) Single-bundle or double-bundle for anterior cruciate ligament reconstruction: a meta-analysis. Knee 21:28-37

46. Maeyama A, Hoshino Y, Kato Y et al (2018) Anatomic double bundle ACL reconstruction outperforms any types of single bundle $\mathrm{ACL}$ reconstructions in controlling dynamic rotational laxity. Knee Surg Sports Traumatol Arthrosc 26:1414-1419

\section{Publisher's Note}

Springer Nature remains neutral with regard to jurisdictional claims in published maps and institutional affiliations.

Ready to submit your research? Choose BMC and benefit from:

- fast, convenient online submission

- thorough peer review by experienced researchers in your field

- rapid publication on acceptance

- support for research data, including large and complex data types

- gold Open Access which fosters wider collaboration and increased citations

- maximum visibility for your research: over $100 \mathrm{M}$ website views per year

At $\mathrm{BMC}$, research is always in progress.

Learn more biomedcentral.com/submissions 